\title{
Exploring the Perceptions of the First Year Students on the Role of Tutors in Enhancing Learning. The Case of One South African University
}

\author{
Dr Patricia Muhuro \\ Senior Consultant, Teaching and Learning Centre, University of Fort Hare \\ Email: pmuhuro@ufh.ac.za \\ Prof. S. M Kang'ethe \\ University of Fort Hare, Department of Social Work and Social Development, Box X1314, ALICE. 5700, South Africa \\ Email: skangethe@ufh.ac.za
}

Doi:10.5901/mjss.2014.v5n27p991

\begin{abstract}
This article endeavoured to empirically explore the perceptions of first year students attending tutorship programmes on the services of the tutors. The study used mixed methods of qualitative and qualitative approaches with qualitative approach being the dominant. The study therefore used a case study and a mini survey as designs with an interview guide and a questionnaire as research instruments. Document analysis, focus group discussions and interviews gathered qualitative data while a questionnaire was used to gather quantitative data. Findings indicate that tutorials were a panacea (beneficial) to the student support programme, but lacked professional discipline and integrity. On the other hand tutees embraced low confidence with the tutors, most were only interested in the marks that tutorials gave and not serious learning, and tutorials were viewed to be creating dependence syndrome for the learners. The paper recommends that tutors selection criteria be strengthened and the coordinators strengtrhen the monitoring and coaching of the tutors. The support programme also need to educate the students of the importance of the tutorial programmes especially during orientation.
\end{abstract}

\section{Problem Statement}

The role of tutors in the continuum of teaching especially in higher education cannot be overemphasized. This is especially important in universities with large student populations that make it difficult for instructors to have adequate student-teacher contact. While the role of tutors may be undermined due to the fact that they may not have underwent professional training (Gordon, 2009), these researchers hypothesise that the role of tutors in many institutions of higher learning is critical in bolstering the learning environment. However, it is important that the views, attitudes, opinions of students serving as tutees are tapped to give insight of the possible benefits ( panacea and possible gaps (perfidy) of the role of tutors in enhancing their learning. This validates carrying out an investigation in one of the universities that make use of tutorials as a student support program.

\section{Operational Definitions}

While the word panacea means a cure of all the maladies, it is here operationalized to mean benefits or desirable events. The word perfidy that means treachery or being trickery is hereby operationalized to mean undesirable events.

\section{Background of the Study}

Broadly defined, while tutors could be any teaching professional offering academic support, they are usually senior students or peers who are deemed to have more knowledge and learning experiences than their colleagues and are given the task of supporting learners in tandem or alongside classroom teachers (Topping, 1998; Chin, Jerome \& Estrada, 2011). Most students entering higher education struggle with understanding concepts, applying the right learning strategies and using the correct academic language (Scott, Yeld \& Hendry, 2007, Thomas, 2000). Such learning challenges require sustained support to foster effective learning and hence the role of the tutors become critical. It is usually understood that they may not necessarily be as good as the teachers, but usually consist of the well 
knowledgeable students who are also willing to help others in learning (Horn \& Jansen, 2008). Tutors reinforce what teachers teach by simplifying complex concepts, procedures and learning processes (Colvin \& Ashman, 2010; Powell, 1997).

Undeniably, Colvin \& Ashman (2010) assert that the roles of tutors are complex and may include advisory services, mentoring, monitoring learning progress, directing students to appropriate support services, coaching, and administration . In the case of coaching, tutors need to apply appropriate pedagogical strategies to assist others to master subject content knowledge. Tutors ought to employ collaborative and individualized learning strategies so as to allow all tutees to participate in the learning tasks and take responsibility of their learning. However, De Smet, Van Keer, \& Valke (2008) assert that just putting a group of students together is no guarantee that learning takes place. Instead, careful planning of content and effective tutorial strategies are necessary to achieve the desired goals. However, most of the challenges that implementation of tutorials face center around different understanding and expectations of the teachers, tutors and tutees of the role of tutors (Colvin, 2007), tutor professional skills in terms of attitudes, tutoring strategies and personality (Roscoe and Chi, 2008), tutee characteristics and teacher support (Topping, 2001). Therefore, many issues have to be taken into account when determining tutee roles. Importantly, a very thorough selection process is needed to ensure that tutors are picked on grounds of academic competence, and possessing leadership skills. This is to enable to provide holistic support that the students need. As such, it is paramount that tutors are morally and ethically grounded. This means that they must be well behaved in order to earn themselves respect from the tutees. It is a pity that some tutors are accused of poor professional misconduct and poor mastery of pedagogical skills (Powell, 1997; Horn \& Jansen, 2008). This raises doubt about the credibility and criteria used to select the tutors for their roles. In some institutions, there could be policies that indicate the need to give preference to certain tutor qualities and preferances for tutorship posts. This, then can throw the whole fray of professional selection into disarray. In light of the above it appears that a good judgment of the selection of tutors for them effectively perform their duties is critical. Hence, the tutor role can be deciphered by empirically tapping the opinions, attitudes of first year students.

\section{Methodology}

\subsection{Research Approach}

The study adopted a mixed method approach meaning that more than one approach was found suitable to guide the research process. While the use of the two approaches bolstered the study, it is good to point out that the study was dominantly qualitative (Bergman,2008). The importance of mixed method is its ability to connect theory and practice and thereby making the study adequately understandably and well conceptualized (Creswell, 2009)

\subsection{Research Design}

The study adopted concurrent mixed method triangulation design employing a mini survey and a case study (Teddlie \& Tashakkori, 2009).

\subsection{Sampling Frame}

The sampling frame composed of lists of tutors working in different academic disciplines and the list of students who were members the institution under the study. From the student list, almost one thousand were tutors in the various academic disciplines and three thousand five hundred were first year students.

\subsection{Unit of Analysis}

The tutorial program was the unit of analysis. All the information sought in the study centred around first year students' views of the role of tutors in enhancing learning.

\subsection{Sample selection and procedures}

The participants for the study were purposively sampled from those enrolled in the first year of their study. These participants included those students who were repeating some courses in the first year. It was important to select first year students because they interacted with tutors frequently and had firsthand experience in the tutorial delivery. This 
helped to understand whether tutorial roles enahnced learning as highlighted by many scholars (Andrews \& Clark, 2012).

\subsection{Research Methods and Instruments}

Since the study used mixed methods, questionnaire interviews were used to gather quantitative data. This was facilitated through the use of a questionnaire. Questionnaires are tools that gather the data within a short period of tome (Creswell, 20009)The qualitative data was gathered through conducting in-depth interviews by the tutor coordinators, and focus group discussions with the tutees. The in-depth interviews and focus group discussions used an interview guide. Focus group discussions helped to provide insights on the missing details through probing (Krueger \& Casey, 2009).

\section{Research Domain}

The selection of the study domain was determined by many factors such as the diversity of the first year student enrollment as reflected in the institutional demographic information, the existence of a tutorial program, relevant policies on tutor selction, conduct and roles.

\section{Ethical and Legal Considerations}

In order to adhere to ethical requirements, permission was obtained from the research ethics committee of university to gain access to documents and to interact with the students. Apart from the permission from the gatekeepers, each of the participants was allowed to freely consent to participate in the study (Leedy \& Omroid, 2010). This was achieved though a letter explaining the purpose of the study and an accompanying consent form to confirm willingness to participate. The researchers upheld the confidentiality of participants by using anonymous codes and pseudonyms when presenting and reporting on the data (Cresswell, 2009).

\section{Data Analysis and Interpretation}

Given that most of the data was qualitative, the data was analysed inductively. This means that emerging themes were coded, and placed into appropriate categories. Data was presented using verbatim responses to illustrate tutee views where appropriate.

\section{Data Credibility and Trustworthiness}

Data credibility was achieved through a pilot study of the survey with ten tutees. This helped to correct inconsistencies within the questionnaire and an interview guide. The triangulation of methods also ensured that the weakness of one method was countered by other methods.

\section{Limitations of the Study}

Tutorials takes many forms (Topping, 2001) and therefore the way tutees experience the services of the tutor may differ depending on factors such as tutees personality, learning preferences and dispositions. Therefore, the study findings may differ if students characteristics are different. Another limitation is that the study excluded lecturer views, whose contribution could also enrich the study findings.

\section{Findings}

\subsection{Tutorials are a panacea to the learning process}

Study findings indicated that a few tutees appreciated the role the tutors were doing by offering their time and service to steer the tutorial sessions. These tutees who valued the tutors indicated that tutorial classes were especially very important to prepare them for the tests and examinations. The following sentiments support the finding. To this end, some students indicated they wanted more sessions, tutors to increase more sessions and more questions

Tutors help us handle the tests with confidence. We indeed learn a lot. (Resp 49, questionnaire response). 
We want tutorial sessions to be increased(FG2, response).

We would like to be given more assignments (FG4, response).

Tutors are good. For example my tutor is a good person who takes his job seriously. I attend her sessions on a daily basis (FG1response).

Perhaps this sends signal to the possible benefit espoused in student this support program. This is because student support programs have been conceptualized to fill in any possible learning gap that the lectures may not have adequately covered. Additionally, they are supposed to offer the student a peer approach to responding to the classroom lapses that the student may have had. This finding, therefore, agrees with some literature that indicates the value and benefits of tutorials to students' learning. This therefore points to the need to strengthen such a program.

\subsection{Tutees low confidence with the tutors.}

In contrast to the above finding pertaining to the experiences of the tutors, some tutees expressed low confidence with the tutors. This is because a number of the tutors displayed low subject content knowledge. This, in these researchers' contention presents a dreadful state of affairs to the tutorial program which is supposed to be a core academic student support strategy. This could mean many things. Perhaps the selection criteria of the tutors was weak, or the process was not adequately and professionally conceptualized. This calls for more scrutiny on the content knowledge of the tutors as well as their pedagogical skills, their level of motivation, passion and their disposition towards helping the tutees. The following statements support this claim:

These tutors are in fact not helping enough. They sometimes come to confuse us and do not appear to have mastery of what they teach (Resp 23, questionnaire response).

Some tutors are very unprofessional because they sometimes provide us with wrong answers . I have developed low confidence with them( Resp,56, questionnaire response).

Tutors don't seem to have an understanding of the course. We think they should be adequately screened before they are employed (Resp 10, questionnaire response).

These sentiments should considered if the tutorials are to be taken seriously. This is because the number of comments could be an indicator that what the few students indicated was not a bias. This sends the bell to the program coordinators to go back to the drawing board and assess their selection criteria. Perhaps widening the scope of the selection criteria to include some instructors from different departments and disciplines could help in coming closer to the desirable tutors.

\subsection{Tutors lacking professional discipline}

On students' experiences and their perceptions over the tutors roles, many students expressed dissatisfaction on the professionalism of their tutors. For example some failed to come for class while the tutees waited in vain. The following quotes support the finding.

Tutors do nothing in this course because we only see them when we are about to write tests, they do not attend sessions (Resp 23, questionnaire response).

I have not seen any one of the tutors frequently (Resp 41, questionnaire response).

The tutors must take their jobs serious (Resp 81, questionnaire response).

Tutors should attend tutorial sessions weekly and not just before a test (Resp59, questionnaire response).

Tutors have to be well informed and find as way to interact with students (Resp 46, questionnaire response).

Tutors never came to class they get paid for northing (Resp 23, questionnaire response).

Tutors must be available every time we need them (Resp 45, questionnaire response).

I went to a tutorial three times but my tutor never pitched up (Resp 31, questionnaire response).

We are struggling to find our tutors and our venues (Resp 27, questionnaire response).

You people should make sure that tutors are serious about the work because most are not attending or conducting tutorials properly(Resp 42, questionnaire response).

I don't attend the tutorials because the few times I have gone, the tutor never attended. (Resp 33, questionnaire response).

They must employ tutors who have skills and knowledge(Resp 11, questionnaire response).

Tutors should know various methodologies to motivate students to avoid being bored in the sessions (Resp 20 questionnaire response). 
From the management of tutorial programs, the scenario presented above by the tutees is very worrisome. It is an indicator that some of the tutors selected were not the right ones. This may point fingers to the selection team, and the monitoring of the tutorial program. It may also mean that the fulfillment of goals and objectives embedded in the whole of student support programmes was at stake and could probably prompt are conceptualization of the support programmes generally if the student support program is to read adequate dividends. Such a scenario is likely to lead to low throughputs, low performance and low retention.

\subsection{Most tutees only interested in getting marks from tutorial sessions}

Contrary to the situation above in which tutors are presented as professionally irresponsible, findings from the analysis indicate that most tutees were not interested in the learning through tutorials other than the marks that was awarded for tutorial attendance. The following quotes reflect this finding:

I think tutorials should be conducted on time and must award marks ((Resp 8, questionnaire response).

All of us want to sign the register so that we could be awarded marks for attendance(Resp 5, questionnaire response). I have never attended a tutorial session(Resp 2, questionnaire response).

Apparently, the issue of students getting interested in marks without learning is a possible cankerworm that could destroy students learning, their quality and is also a sure recipe of producing half baked graduates into the labour markets. This needs to be annihilated altogether. To these researchers, this is a sad state of affairs considering the efforts of the tutorial program managers and the University at large for instituting students' support programmes as a vehicle of enhancing students learning process. This is because tutors are paid for the service. Perhaps what these researchers worry about most is what could have diminished the students' morale, motivation and the thrust to learn. Perhaps the tutorial program or the whole of the student support program was not adequately motivating to both the tutors and the tutees alike. Alternatively, the students could have fallen prey to the behaviours of a number of learners who upon entry into the institutions of higher learning change their behavior negatively and thereby affecting their tempo, disposition and motivation towards learning. This therefore opens a dialogue to determine the possible de motivational forces from both the students and the university milieu generally.

\subsection{Tutorials creating dependence syndrome}

On tutorials, findings from tutees indicated that some tutees were developing a dependence syndrome that made them to ask for the services outside their scheduled timeframe. This created confusion because the tutors may not be available all the time. There were also other dynamics in that tutors were also paid according to the sessions they attended and there were institutionally prescribed maximum number of sessions that they could support students. This finding is supported by the following sentiments:

We should be allowed to have tutorials as much as is possible in our free time

Tutors should avail themselves when students need help

Tutorial sessions should be attended on daily basis especially when there are impending tests.

In these researchers' contention, the development of dependence syndrome is unfortunate and ways and means should be applied to make the tutorial sessions developmental. This is because if not adequately handled, it could resort to surface learning where students would like to rehearse the answers especially to pass the tests and not to understand. Perhaps the organizers of the program need to constantly explain the need for the support programs to be developmental and not to be a vehicle of passing tests and examinations. This is to ensure that students comprehend and internalize the content they learn.

\section{Discussion}

Apparently, there seems diametrically opposed views from the students concerning the role of tutors. On one hand , tutors are regarded as valuable professional figures who provide clearer understanding of subject knowledge and therefore contributing significantly to the promotion of student support program. This perception could be supported by the fact that most tutees have been passing their examinations without serious hitches. This finding thus supports the view that tutors are a valuable in bolstering learning for students who have different levels of subject mastery (De Smet et 
al. 2008). This is mainly achieved when students attend tutorials regularly and are adequately taught . Tutoring also supports the tenets of social learning theory which postulates that students learn best when they are supported to reach the zone of proximal development from the knowledgeable others (Vygotsky, 1978). In this case, the tutors and other students in the small tutorial group serve as the "knowledgeable others" who simplify learning content.

However, effective implementation of tutor roles depend on both the student side and on the tutors. Students need to be participatory to effectuate a significant success in their learning. For instance students need to attend regularly and participate in the assigned tasks. Sadly though, this study found that some students were too dependent on tutors and were not willing to actively take charge their learning. Most of such students attended tutorials just because they wanted marks, thus expected to be spoon fed . In other words, tutorials were a quick fix process to their learning challenges. Yet, De Smet et al (2008) found out that tutorials are beneficial to those students who attend them regularly and seriously. Those students who did not attend regularly seemed to have negative view of tutor roles once they failed tests and assignments. This finds support in a study by Felder (2007) who found that tutees who were used to be spoon fed resisted continuous independent learning strategies. Such students have high possibilities of dropping out because they are not able to make sense of information. This finding about the tutee behavior and disposition seem to support the view that students who are used to rote learning, find it uncomfortable of to take responsibility of their learning.

On the part of the tutors, the findings suggest negative attitudes towards tutees and poor professional conduct because tutors were not attending sessions regularly and were not communicating clearly with their tutees. Such a situation calls for tight monitoring of tutor conduct as expoused by most tutorial advocates ( Gordon, 2009; De Smet et al., 2008).

In this study, document analysis of selection policies showed that tutors were appointed on academic merit, yet first year students felt that they were not academically prepared, because of poor content mastery and poor tutoring approaches. Tutors who lacked subject content knowledge, were perceived as confusing students with inappropriate explanations. Roscoe \& Chi(2008) assert that poor content mastery implies that the tutor himself is unable to clearly connect theory and practice. If they are not offered opportunities for revising the content, tutors likely to resort to directive tutoring where they provide answers without explanations in order to hide their inadequacies. Directive tutoring perpetuates surface learning (Roscoe \& Chi, 2008). This finding also supports views by scholars who argue having a higher grade in the subject does not necessarily imply that the tutor uses productive learning methods (Krause, 2005). This finding therefore has implications on on tutor professional development.

\section{Way Forward}

Since the study revealed that tutors play a pivotal role in the continnum of learning, is important that the tutor roles are clearly defined and communicated to students. This will assit in clarifying expectations and possibly minimise tutee discontent. Importantly, tutor conduct in the classroom in terms of professional conduct, pedagogical knowledge and attitudes was more important to tutees, hence such skills and qualities need to be reinforced through training, monitoring and coaching. This is because the study found that academic merit was not the only quality that enabled the tutor to adequately perform their roles. Therefore tutorial program managers should use several criteria when appointing tutors if various students expectations are to be met. The tutors selection criteria needs to be strengthened and the coordinators strengtrhen their monitoring of the tutors. The support programme also need to educate the students of the importance of the tutorial programmes especially during orientation.

\section{Conclusion}

The study findings revealed that the first year students had differing views on the roles of tutors in enhancing students learning. This could be attributed to different expectiations of what tutors should do to enhance students learning. On one hand some first year students felt that tutors provided academic and emotional support and this boosted confidence and enhanced learning. Students who held such views even suggested that more tutorial sessions should be conducted. However, among these first year students were those students who perceived tutors as quick fix to their learning challenges and expected tutors to be available all the time. This is undesirable because tutoring ought to promote lifelong and independent learning rather than dependance

The study findings revealed that the first year students had differing views on the roles of tutors in enhancing students learning. This could be attributed to different expectiations of what tutors should do to enhance students learning. On one hand some first year students felt that tutors provided academic and emotional support and this boosted confidence and enhanced learning. Students who held such views even suggested that more tutorial sessions should be 
conducted. However, among these first year students were those students who perceived tutors as quick fix to their learning challenges and expected tutors to be available all the time. Such students felt that the tutors were not performing their roles of making them pass. Also tutees were of the opinion that most tutors had poor subject content mastery and poor professional conduct. They highlighted cases of tutors not attending sessions and other times made students to sign the register without holding the session. For that reason, students attendance tutorials dropped as they saw no benefit in the program. Such a finding has implications on continuous professional development and monitoring of tutors to ensure that they have a good grasp of the content that they teach.

Since most higher education instituions heavily rely on tutors for academic student support, they may be need to infuse clinical supervision and constnat monitoring of tutors to ensure that this support program is achieving its objectives.

\section{References}

Andrews, J.,\& Clark,R. (2012). Peer Mentoring Works. How Peer mentoring Enhances Student Success in HE. Birmingham: Aston University.

Bergman, M. (2008). Advances in Mixed Methods Research: Theories and Application. London : SAGE.

Bryman,A. (2012). Social Research Methods (4th Edition ed.). Open University Press: Oxford.

Chin, T., Rabow,J.,\& Estrada,J. (2011). Everything you wanted to know about a tutor. Temple University Press.

Colvin, J.W. (2007). Peer tutoring and social dynamics in Higher education. Mentoring and Tutoring, 15, (2), 165-181.

Colvin, J.W., \& Ashman, M. (2010). Roles, risks and benefits of peer mentoring relationships in higher education. Mentoring and Tutoring, 18 (2),121-134.

Creswell, J. (2009). Research Design: Qualitative, Quantitative and Mixed Methods Approches (3 ed.). Thousand Oak: SAGE.

De Smet, M. Van Keer, H.\& Valke, M. (2008). Cross age Peer tutor in asynchoronus dicsussion groups: Studying the impact of tutors labelling their interventions. Researchgate.net. doi:10.1111/j.1365-2729.2008.00284.x

Gordon, E. (2009). Five ways to improve tutoring programs. Phil Delta Kappan , 90 (6), 440-445.

Gregogry, G., \& Chapman, C. (2007). Differentiated instructional strategies : one size doesn't fit all (2nd ed ed.). Thousand Oaks: Crowin Press.

Horn., P., \& Jansen, A. (2008). Do tutorial programmes influence performance of economics students. A Case study of the Economics 178 course at the University of Stellenbosch. Cape Town, Western Cape, South Africa: Unpublished paper. Draft paper Economic Research Council.

Johnson, B. \& Christensen,L. (2012). Educational Research: Quantitiative, Qualitative and Mixed Approaches. (4th ed.). Far East Square: SAGE Publications.

Krueger,R.A.,\& Casey, M.A. (2009). Focus Groups: A Practical guide for Applied Research (4th Edition ed.). Thousand Oaks Calif: SAGE.

Kuh, G. (2007b). What college student data tell us about student readiness. AACU Peer Review , 9 (1), 4-8.

Krause, L. (2005). Serious thoughts about dropping out in first year. Studies in Learning , Evaluation and Innovation , 2 (3), 55-68.

Leedy, P. D. and Ormroid, J.E. (2010). Practical Research: Planning and Design (9th ed.). Pearson.

Lemens, I and Maitlad, E. (2008). Meeting social and emotional needs of students through peer tutoring. Acta Academia , 43 (4), 127151.

Lemmens, J. (2010). Students readiness for university education. University of Pretoria. Pretoria: Unpublished doctoral thesis.

Letseka, M.,\& Maile,S. (2008). High university dropout rates: a threat to South Africa's future. Pretoria: Human Science Research Council: Cape Town.

Pascarella, E.T., \& Terrenzini, P.T. (2005). How College Affects Students: A Decade of Research (Vol. II). Jossey Bass.

Roscoe, R. D., Chi, HHM. (2008). Understanding tutor learning, knowledge building and knowledge telling. Review of Educational Research, 77, 534-574.

Sarantakos, S. ( 2005). Social research (3rd Edition ed.). London: Macmillan.

Terreblanche, M., Durrheim,K., \& Painter, D. (2007). Research in practice. (2nd ed). Cape Town. University of Cape Town Press.

Tashakkori, A. \&. Teddlie, S. (2009). Mixed methodology: Combining qualitative and quantitative approaches. Applied Social Research Methods Series (Vol. 46). Thousand Oaks, CA: SAGE Publications.

Thomas, E. (2000). Ties that bind. A social network approach to understanding student integration and persistence. Journal of Education ,75, 591-615.

Thomas, L.,Quinn, J., Slack, K., Casey, L. (2012). Effective Approaches to retaining students in Higher Education. Stoke on Tent: Institute For Access. Stafforddshire University.

Vygotsky. (1978). Mind and Society. Development of Higher Psychological Process. Harvard University Press, Cambidge, MA. 